\title{
Short Proposal
}

Proposal title and acronym: The AMAAL project - Ask Me Anything About the Law

Keywords (max 5 words): citizen science; legal advice; access to justice; environmental matters; collaborative platform

List the type of participants (researcher, stakeholder), organization name and country

\begin{tabular}{|l|l|l|}
\hline Type of participant & Organization name & Country (of organization) \\
\hline SME & Liberate Science GmbH & Germany \\
\hline Research project & Sensing for Justice & Italy \\
\hline
\end{tabular}

\section{EXCELLENCE}

\subsection{Strength and innovation of the idea}

\section{Describe the core idea of your application.}

One of the recurring challenges for small-scale citizen science communities across Europe is the scarce access to legal information and legal advice. For example, the civic monitoring of oil impacts in the South of Italy (Basilicata) and the mapping of air pollution in the Netherlands (Brabant). For such citizen science communities, the law can be a resource, to leverage results and produce concrete change advancing legal claims based on rights. Yet the law can also be an obstacle, when it is used against communities or due to the legal provisions to be met.

For example, the law can be utilized for making civic requests under the United Nations Economic Commission for Europe (UNECE) Convention on Access to Information, Public Participation in Decision-making and Access to Justice in Environmental Matters (i.e., the Aarhus Convention). These requests provide avenues for a meaningful engagement of local actors with environmental information and decision-making. Navigating these landscapes may be difficult without support. Additionally, local actors may also risk legal consequences for their monitoring, such as tort and defamation claims from companies or governments that try to discourage their initiatives.

Legal advice remains expensive and not all citizen science communities can afford it, hence it is often practically inaccessible to concerned people. Free legal aid in Europe remains scarce, and - if accessible - it is primarily in cities. There is a disconnect between legal knowledge, advice and ongoing research, and the needs of small-scale citizen science initiatives.

In the AMAAL project, we will provide accessible legal aid for environmental citizen science communities. We will implement an "Ask a legal question" tool, in order to bring together citizen scientists active on the ground and legal experts. Resulting questions and answers will be published on the open access publishing platform ResearchEquals.com, authored jointly by civic actors and legal experts. We will provide ephemeral and secure virtual spaces for the community to help further facilitate the dialogue between civic actors, legal experts, and peer citizen science communities (e.g., around initiating a court case based on the collected data). This knowledge will be useful for legal experts to refine their knowledge of citizen science and explore possible applications in their legal practice, along with advancing legal research.

\section{What is new or different about it? Has it been tried before?}

- Our source of inspiration is a comparable United States (U.S.) initiative, which proved to be valuable and useful for citizen science communities:

https://citizenscience.org/get-involved/working-groups/law-policy/ask-a-legal-question/

- To date no such "Ask a legal question" for citizen science projects has been implemented in Europe; it will be a challenge to transpose lessons from the U.S. to 
Europe, adapting the idea to the conceivable needs of European citizen science groups.

- Whereas the platform in the U.S. is a uni-directional, citizen-expert/student communication channel, we intend to build a truly collaborative platform where legal research is deployed by the demanding actors, and by those legal experts and peer citizen science more experienced with the legal dimension.

\subsection{Relevance to the call}

What SDG does your idea address? N. 10 (inequalities), 13 (climate action), 16 (justice).

Which territories will the pilot cover? States within Europe, starting from Italy, Germany, France and The Netherlands where there are experts and civic groups willing to join the pilot.

Is this your first citizen science project? Do you have expertise in project design, citizen engagement, data management, etc.? Team members have experience with running large open science projects and citizen science projects, such as the Reproducibility Project: Psychology and the Sensing for Justice project. Such projects included strategic design, societal outreach and data management.

\subsection{Team}

What kind of stakeholders are involved? Who are the key stakeholders? Citizen science communities; local environmental activists; SMEs working on environmental sustainability; legal experts; law students; associations active in the environmental field such as the Italian Centre for Addressing and Mediating Environmental Conflict - Systasis

http://www.systasis.it/.

Brief Bio (personal data of the academic and non-academic members - Title, surname, first name, full affiliation (department/centre, institution and e-mail address).

- Dr. Chris HJ Hartgerink, Liberate Science GmbH, CEO \& Founder, chris@libscie.org

- Dr. Berti Suman Anna, Digital Economy Unit, The European Commission Joint Research Centre, the SensJus Project principal investigator, Anna.BERTI-SUMAN@ec.europa.eu

\subsection{Data management}

What (if any) data do you intend to gather or produce? How much of this will be openly available? All authored questions and answers will iteratively be published on the platform ResearchEquals.com. Any (non personal) data collected to investigate specific questions and provide initial answers will be published there as well.

\section{IMPACT}

\subsection{Impact of the actions}

What problem/issue does your pilot address? Up to now, European environmental citizen science initiatives - especially small-scale ones - rarely explored the potential of using the law for supporting their claims. They also rarely have a structure in place able to respond in case they have to face a lawsuit. In the U.S., both researchers, legal scholars and communities often turned to the legal potential but also the legal implications of civic monitoring. Europe is lagging behind with a few exceptions. On the one hand, citizen science can be a way of claiming, enforcing, and strategically litigating rights. On the other hand participants may be exposed to liability and other legal risks associated with the practice. Possible legal risks are already visible in forms of 'silencing' environmental defenders (which may also rely on citizen science) such as the Strategic Lawsuits Against Public 
Participation. This is particularly frequent in the U.S. but growing also in (especially Eastern) Europe. Field research conducted for the Sensing for Justice project demonstrated that citizen scientists are mostly unaware of or unprepared to face potential legal risks stemming from their monitoring activities. This occurs not only in faraway lands such as the rainforest, but also in the Global North, such as our field experience with the local civic sentinels in Basilicata, an oil-rich region of Southern Italy, shows. Improving the legal preparation of such projects may increase litigation-oriented thinking, enable more impact of the projects, and better assess and mitigate legal risks.

What will be the potential impact of the pilot on society/ the community / social targets? Citizen science communities operating in potentially risky contexts will be able to obtain at an early-stage guidance on how to face possible legal risks. All citizen science communities, even those not dealing with legal risks, will be offered ways to address 'standard' questions related to privacy and data protection law, for example, and to get advice from experts and peer citizens on how to use legal remedies for their actions.

And on the production of new knowledge? The new knowledge produced will stem from a participatory research where citizen science meets legal investigation. This knowledge pool will shield citizen scientists but also leverage actions and inspire other communities to make a wise use of the law. All outputs will be published open access. Practically, most frequently asked questions from the community chat will be compiled into FAQs documents but will also become part of an evolving legal research data pool, precious for practitioners, communities and researchers. The learning may also be the basis for future strategic litigation grounded on citizen science-gathered evidence.

\section{IMPLEMENTATION}

\subsection{Planned activities}

Briefly describe the activities to be carried out.

- Identify environmental citizen science projects in need of legal advice and co-design the tool with them;

- Communicate and promote the "Ask a legal question" tool;

- Integrate all questions asked in an online openly accessible and 'live' resource.

Which pilot activities will involve citizen science principles (See for example the ECSA Principles of Citizen Science)? Our pilot will involve Principle 1 on citizens' leading and meaningful role in co-shaping the project; Principle 3 on mutual benefits for citizen scientists and (legal) researchers; Principle 5 and 8 on recognition and acknowledgement; Principle 7 on making resulting data available and Principle 10 on ethical and legal integrity.

\subsection{Project duration}

Project start date and duration. Start date: May 2022. Duration: 12 months.

\subsection{Requested Total Budget: 45,000EUR}

Briefly explain the main cost items: Project manager (part time, 6 months) - 17,200EUR; Tool development (open source): 10,000EUR; Tool communication and promotion: 2,800EUR; Rewards to participants (e.g. book vouchers): 5,000EUR; tool launch, mid-term encounters and final event + publication: 10,000EUR. 